\title{
RETROSPECTIVE ANALYSIS OF TREATMENT OF TUBERCULAR PLEURAL EFFUSION
}

Satish Motiwale ${ }^{1}$, Ravi Dosi ${ }^{2}$

\section{HOW TO CITE THIS ARTICLE:}

Satish Motiwale, Ravi Dosi. "Retrospective Analysis of Treatment of Tubercular Pleural Effusion". Journal of Evolution of Medical and Dental Sciences 2014; Vol. 3, Issue 21, May 26; Page: 5677-5679,

DOI: $10.14260 /$ jemds/2014/2647

ABSTRACT: To determine the effect of adjunct therapy, we carried out a prospective cohort study on 190 patients with tuberculous pleural effusion during May 2003-April 2004. Patients were divided into 3 groups. All groups were treated with anti-tuberculosis (TB) drugs for 6 months; in group 2 ( $\mathrm{n}=$ 46) prednisolone, $30 \mathrm{mg} /$ day for 10 days, was added; group $3(\mathrm{n}=78)$ were given paracentesis to remove fluid. Fever and constitutional symptoms disappeared faster in group $2(\mathrm{P}>0.05)$. After 10 days, there was a significantly greater reduction in the size of pleural effusion in group 2, but after 6 months the difference was not statistically significant. We found steroids and therapeutic paracentesis are not necessary in the management of TB pleural effusion.

KEYWORDS: Steroids.

INTRODUCTION: World Health Organization (WHO) recommends, tuberculous pleural effusion to be treated according to the category I regimen: 2 months with 4 anti-tuberculosis (TB) drugs followed by 4 months with 2 anti-TB drugs. ${ }^{1}$ Adjunct therapy with steroids or pleural fluid aspiration until dryness have been recommended by some researchers. ${ }^{2-5}$ Steroids in conjunction with anti- infective drugs may be appropriate in particular forms of TB such as tuberculous meningitis and pericardial and pleural disease. ${ }^{6}$ Cohen et al does not recommended routine use of steroids in tuberculous pleural effusion unless there are acute symptoms such as fever, chest pain or dyspnea that are disturbing to the patient and keeping in consideration several drug interactions.7-9

AIM: The aim of this study was to determine the effect of steroids and paracentesis on tuberculous pleural effusion with regard to symptoms, size of the effusion and complications like resolution, pleural thickening.

METHODS: We carried out a retrospective study of all patients with tubercular pleural effusion In SAIMS hospital in Indore from May 2013 to April 2014. The study was explained to all patients and informed consent was taken from them. For all participants, the total duration of anti-TB drugs was 6 months all were registered under DOTS Category I RNTCP.

The patients in group A $(\mathrm{n}=35)$ were treated with anti-TB drugs only for 6 Months as per DOTS recommendations. ${ }^{1}$ Those in group $\mathrm{B}(\mathrm{n}=35)$ were given anti-TB drugs under Category I plus steroids in the form of deflazacort $12 \mathrm{mg} /$ day for 10 days. The patients in group $\mathrm{C}(\mathrm{n}=35)$ were treated with anti-TB under DOTS Category I drugs and thoracocentesis. Daily case details \& records were taken.

For statistical analysis, the chi-squared test was used as appropriate. $\mathrm{P}<0.05$ was considered significant throughout the analysis. 


\section{ORIGINAL ARTICLE}

RESULTS: The total number of patients was 110, 70 males and 40 females. Age range was 25-70 years. There were no significant differences between the 3 groups regarding epidemiological factors.

50 patients had moderate effusions 49 had mild effusions 21 had massive effusions The time of clinical normalcy in the group B [who were treated with steroids] was 4 [standard deviation (SD) 2.8 ] days compared to 10 days (SD 1.7) in the other 2 groups ( $\mathrm{P}>0.05)$.

There were no differences between the groups with regard to extent of pleural thickening. After 15 days, there was $>50 \%$ reduction in the size of pleural effusion in the group having adjunct steroid treatment (group B) compared with $25 \%$ in the other groups.

In all groups, there was progressive reduction of size of pleural effusion up to the third month of treatment. After 6 months there was, however, no statistically significant difference between the 3 groups.

No significant relation was found between sizes of effusion and later pleural Scarring.

DISCUSSION: Steroids have been shown to be beneficial in treatment of TB ${ }^{6,10,11}$ In the study of Misra et al no benefit was shown, even in tuberculous meningitis. ${ }^{12}$ Adjunctive corticosteroid therapy appears to offer significant short-term, but minimal long term, benefit for patients with TB.11

In our study, steroids hastened the recovery of constitutional symptoms And led to early reduction in symptoms, but after 6 months there was no difference between the groups ${ }^{6}$. Steroids bring about more rapid resolution of pleural effusion with less pleural scarring \& thoracocentesis is superior to other treatments. $5,7,13$

In conclusion, corticosteroid treatment and therapeutic paracentesis are not necessary In the management of tuberculous pleural effusion, and have no effect on Extent of residual pleural thickening after 6 months treatment with anti-TB drugs.

\section{REFERENCES:}

1. Maher D et al. Treatment of tuberculosis: Guidelines for national programmers, $2^{\text {nd }}$ Ed. Geneva, World Health Organization, 1997:29.

2. Satya Sri S. Textbook of pulmonary and extra pulmonary tuberculosis, 2nd Ed. New Delhi, Interprint, 1995:82-6.

3. Lee $\mathrm{C}$ et al. Steroids in the treatment of tuberculous pleurisy: a double-blind, Placebocontrolled, randomized Study. Chest, 1988, 94(6):1256-9.

4. Galarza I et al. Randomized trial of steroids in the treatment of tuberculous Pleurisy. Thorax, 1995, 50(12):1305-7.

5. Wyser $\mathrm{C}$ et al. Steroids in the treatment of tuberculous pleurisy: a double-blind, placebocontrolled, randomized study. Chest, 1996, 110(2):333-8.

6. Alzeer AH, FitzGerald JM. Steroids and tuberculosis: risks and use as adjunct therapy. Tubercle and lung disease, 1993, 74(1):6-11.

7. Cohen M, Sahn SA. Resolution of pleural effusions. Chest, 2001, 119(5):1547-62.

8. Matchaba PT, Volmink J. Steroids for treating tuberculous pleurisy. Cochrane database of systematic reviews, 2000, 2.

9. Grange JM, Winstanley PA, Davies PDO. Clinically significant drug interactions with antituberculosis agents. Drug safety, 1994, 11(4):242-51. 


\section{ORIGINAL ARTICLE}

10. Alarifi A, Nylen ES. Dislodging sacred dogmas in combating systemic stress: the case for steroids. Annals of Saudi medicine, 2000, 20(5, 6):358-9.

11. Dooley DP, Carpenter JL, Rademacher S. Adjunctive steroids therapy for tuberculosis: a critical reappraisal of the literature. Clinical infectious diseases, 1997, 25(4):872-87.

12. Kalita J, Misra UK. Effect of methyl prednisolone on sensory motor functions in Stein JH, Daly WJ, eds. Internal medicine, 2nd ed. Boston, Little, Brown \& Co., 1987:1731-48

\section{AUTHORS:}

1. Satish Motiwale

2. Ravi Dosi

\section{PARTICULARS OF CONTRIBUTORS:}

1. Associate Professor, Department of Respiratory Diseases, Sri Aurobindo Institute of Medical Sciences \& Post Graduate Institute, Indore.

2. Assistant Professor, Department of Respiratory Diseases, Sri Aurobindo Institute of Medical Sciences \& Post Graduate Institute, Indore.

\section{NAME ADDRESS EMAIL ID OF THE CORRESPONDING AUTHOR:}

Dr. Ravi Dosi,

Department of Respiratory Diseases,

SAMC \& PGI,

Indore.

Email: ravi.dosi@gmail.com

Date of Submission: 06/05/2014.

Date of Peer Review: 07/05/2014.

Date of Acceptance: 17/05/2014.

Date of Publishing: 20/05/2014. 